\title{
Bleksanger Hippolais pallida - ny for Norges fauna
}

\author{
Inge Hafstad, Magne Myklebust \& Torborg Berge
}

Hafstad, I., Myklebust, M. \& Berge, T. 2004. Eastern Olivaceous Warbler - Hippolais pallida - new to Norway. - Ornis Norvegica 27: 106-117.

Norway's first Eastern Olivaceous Warbler Hippolais pallida was recorded on 12th September 2004. An adult of this species was caught in a mist-net at Titran in the island municipality of Frøya, off the coast of Sør-Trøndelag county in Central Norway. Hippolais pallida was previously on the list of birds recorded in Norway, but due to uncertainty about the identification of grey species of Hippolais, the record was changed in 1994 to that of unidentified $H$. rama/H. pallida. The Titran bird was of the eastern race H.p.elaeica, which occurs regularly in south-eastern Europe and central Asia. It does not breed west of Slovakia, and winters in East Africa, north of Lake Victoria, and on the Arabian Peninsula. Only a few countries in central and northern Europe have records of the Eastern Olivaceous Warbler. The majority of these are from Britain, but it has also been observed in Ireland, Austria, Finland, Sweden and Denmark, and now in Norway. Though several south-eastern European countries have reported a decrease in their populations, Greece and Turkey still hold populations of $100000-150000$ and $500000-5$ million breeding pairs respectively. It is therefore natural to assume a large number of records in northern and western Europe resulting from prolonged spring migration or reversed autumn migration. However, the Alps and the Carpathians seem to make an effective barrier, and in Germany only three records have been reported from 1883-2000. Despite the Eastern Olivaceous Warbler breeding in Austria's neighbouring countries of Slovakia and Hungary, there is only one confirmed record in Austria itself. Britain had 11 records up to 2003, while Ireland had 4 up to 1999. In the Nordic countries a total of eight records have been reported. The two latest records, from autumn 2004, in Norway and Sweden respectively, have not yet been treated by their countries' rarities committees. However, they were both convincingly documented. The Eastern Olivaceous Warbler is a pale and insignificant warbler with few distinct characters. It is easily confused with other Hippolais species like H.rama, H. opaca and H. caligata. It can even be confused with $H$. languida and Acrocephalus dumetorum. As shown in the photos, P1 was about 4$5 \mathrm{~mm}$ longer than the secondaries of the Titran bird. The tail was relatively narrow and straight with long outer tail feathers. The edge of the wing was also straight, excluding Acrocephalus dumetorum, and the shape of the bill excluded $H$. opaca. The bird's plumage was without olive green, resulting in a rather light grey impression, also from above. A general identification of the Eastern Olivaceous Warbler is discussed further in comparison with the possible confusion species mentioned above.

Inge Hafstad, Sørenget 19, 7650 Verdal. E-mail: iha@nofnt.no. Magne Myklebust, Norsk Ornitologisk Forening, Sandgata 30B, 7012 Trondheim. E-mail: vf@birdlife.no. Torborg Berge, E-mail: torborg.berge @mattilsynet.no.

Den 12. september 2004 ble en bleksanger Hippolais pallida for første gang registrert $\mathrm{i}$ Norge, da en fugl ble fanget i mistnett på Titran, Frøya kommune i Sør-Trøndelag. Fuglen tilhørte underarten elaeica som er utbredt i de sørøstlige deler av Europa og østover til Sentral-Asia. Bleksanger forekommer i fire forskjellige underarter i det sørøstlige Europa, Asia og Afrika: Hippolais pallida pallida, H. p. reiseri, H. p. leaneni og $H$. p. elaeica. De tre førstnevnte underartene finnes i Afrika, og vil ikke bli beskrevet i denne artikkelen. For mer informasjon om disse, henviser vi til Svensson (2001a). Med bleksanger menes i denne artikkelen underarten $H . p$. elaeica. Tidligere stod blekspottesanger Hippolais pallida på listen over fuglearter observert i Norge (Gjershaug et al. 1994). Observasjonen ble godkjent av Norsk 
sjeldenhetskomité for fugl (NSKF) i deres årsrapport for 1988 (Bentz \& Clarke 1990). Grunnet dårlig bildedokumentasjon og den generelle usikkerheten som på den tiden rådet rundt sikker bestemmelse av grå Hippolaisarter (jf. Osborn 1993), ble observasjonen i 1994 justert til ubestemt bleksanger/ramasanger Hippolais rama (Gustad 1994). Blekspottesanger ble senere splittet i maurersanger Hippolais opaca og bleksanger Hippolais pallida (Knox et al. 2002).

Bleksangeren var Titrans andre førstefunn for Norge, og stadfestet lokalitetens ry for opptreden av ekstremt sjeldne fuglearter. Landets første nyregistrering på Titran var en gråhodespurv Emberiza spodocephala som ble fanget og ringmerket den 2. oktober 1999 (Solbakken \& Myklebust 2000). Titran ligger på vestspissen av øya Frøya i øykommunen Frøya, i havgapet i Sør-Trøndelag. Frøya smalner av mot vest, og topografien gjør at fugler på høsttrekk langs kysten ender opp konsentrert på vestspissen av øya (Solbakken \& Myklebust 2000). Øyas vegetasjon bestod i utgangspunktet av kystlynghei, som ble vedlikeholdt med sauog storfebeiting, samt lyngbrenning. Bortfall av dette, samt tilplanting av ikke stednære arter, har ført til at deler av øya har fått kratt- og skogvegetasjon. Kystlynghei er likevel fortsatt $\varnothing$ ygruppens viktigste vegetasjonstype.

\section{Funnomstendighetene}

På fredagskvelden den 10. september dro vi utover til Titran; tre timers bilkjøring vest for Trondheim. Da vi våknet opp lørdag morgen 11. september, var det dårlige forhold for å drive med nettfangst. Det blåste og regnet, og først utpå dagen hadde forholdene bedret seg nok til at vi kunne forsvare å åpne mistnettene. Godværet fortsatte å vente på seg, og fangsten ble ikke all verden utover dagen. Søndag 12. september startet med bedre vær og mer fugl i lufta og i nettene. Litt over kl. 13.00 kom Magne Myklebust med beskjed om at vi hadde fanget en kjerrsanger Acrocrephalus $s p$. Vi samlet oss rundt merkebordet og gjorde oss ferdige med den $\emptyset v$ rige fangsten, før vi beskuet kjerrsangeren. Vingen ble målt først, og den var så kort at mistanken umiddelbart falt på busksanger Acrocephalus dumetorum. Med en vinge på $64 \mathrm{~mm}$ (Tabell 1) utelukket vi umiddelbart den mer langvingede slektningen myrsanger A. palustris som har minstemål for vingelengde på $67 \mathrm{~mm}$ (Svensson 1992). Alle de biometriske målene til fuglen (Tabell 1) stemte med busksanger, og til tross for at vi kommenterte at den var uvanlig blek og at stjerten var lite avrundet til å være busksanger, slo vi oss til ro med artsbestemmelsen. Fuglen var en voksen fugl med generelt slitt fjærdrakt, og spesielt slitte vinge- og stjertfjær (Fig. 1-3).

Etter at vi kom hjem, ble bildene vist til Kjetil Aa. Solbakken og Alf Tore Mjøs. De kommenterte bildene, stusset litt på dem, og spurte hvorfor dette ikke var en bleksanger. Da ble bildene straks sendt med e-post til Lars Svensson for sikker bekreftelse. Han fastslo raskt at dette var en bleksanger, og argumenterte blant annet med at P1 var klart lengre i forhold til håndsvingdekkerne enn det en busksanger maksimalt kan ha. Hos busksangeren kan dette forholdet maksimalt være $2,5 \mathrm{~mm}$, mens det hos Titran-fuglen trolig var 4-5 mm. Dessverre ble ikke forholdet målt, men bildene viser tydelig at det må være mer enn 2,5 $\mathrm{mm}$. Videre meddelte Svensson at fuglens farge stemte bedre for en bleksanger enn for en busksanger. Stjerten var relativt smal og rett

Tabell 1. Biometriske mål for bleksanger fanget på Titran 12. september 2004.

- Vingelengde/wing length: $64 \mathrm{~mm}$

- Håndsvingfjær/Primaries: $2 \mathrm{P}=6 \mathrm{P}$ and $3 \mathrm{P}=4 \mathrm{P}$

- Lengde på innskjæring av innerfanen $2 \mathrm{P}$ /length of notch on inner web of $2 P: 13,5 \mathrm{~mm}$

- Notch on 2P: $3 \mathrm{~mm}<\mathrm{SS}$

- Notch on $3 P=\mathrm{SS}$

- $\mathrm{S} 1$ < vingespiss/tip of wing: $15 \mathrm{~mm}$

- Stjertlengde/tail length: $47 \mathrm{~mm}$

- Stjert/vinge Tail/wing: $\quad 0,734$ 


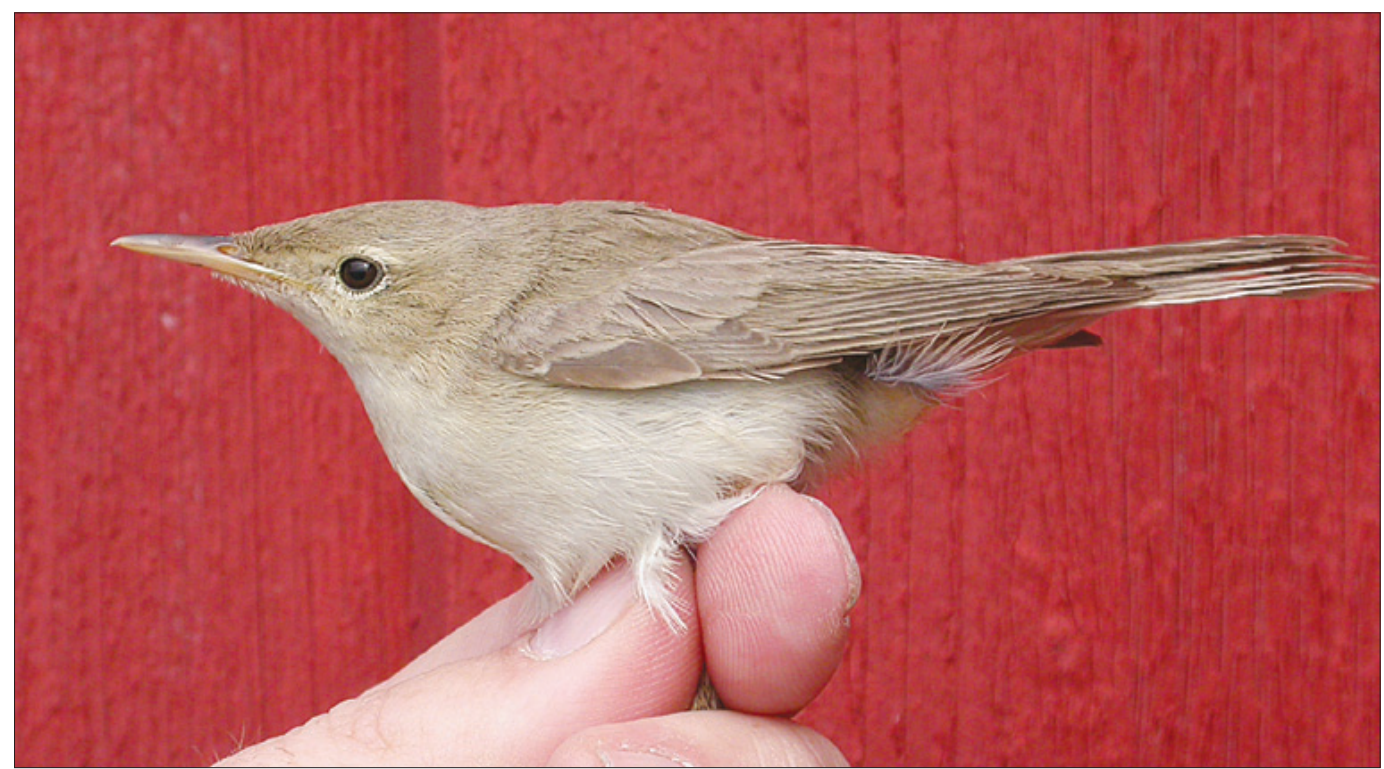

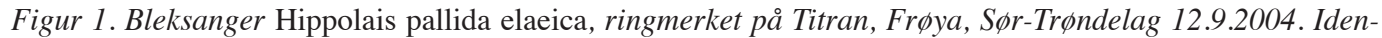
tifikasjon av denne arten er svart utfordrende, men fuglens generelt meget bleke overside og litt merkelige

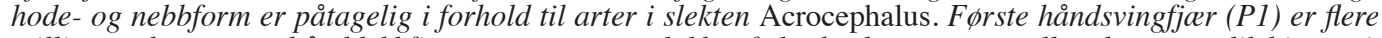
millimeter lenger enn hånddekkfjarene, noe som utelukker f.eks. busksanger som ellers har svart lik biometri. Foto: Torborg Berge.

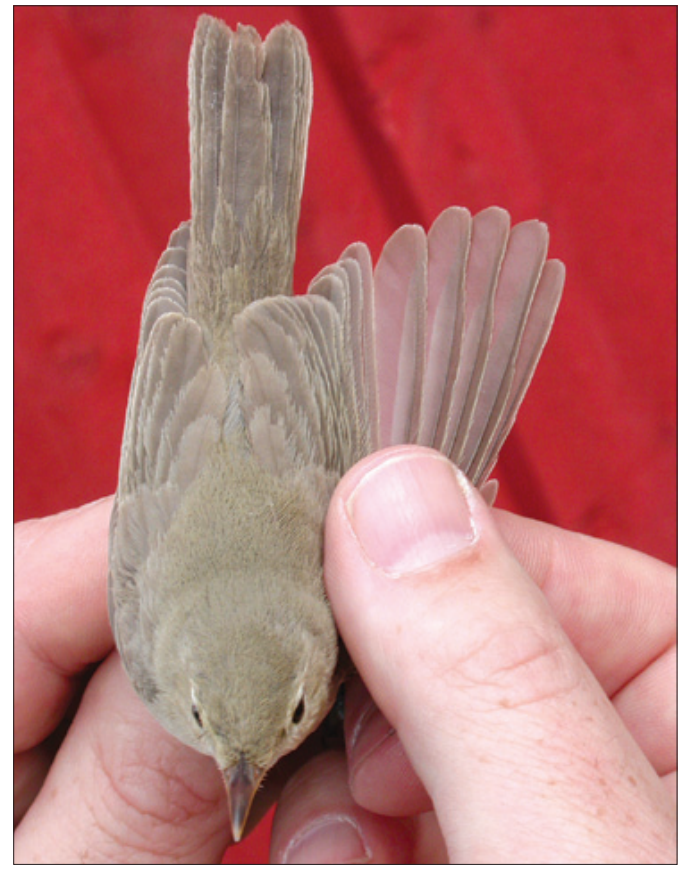

Figur 2. Stjerten er nokså tvert avskåret, med antydning til lysere bremmer på de ytre stjertfjarene. Samme fugl som på Figur 1 og 3. Foto: Magne Myklebust.

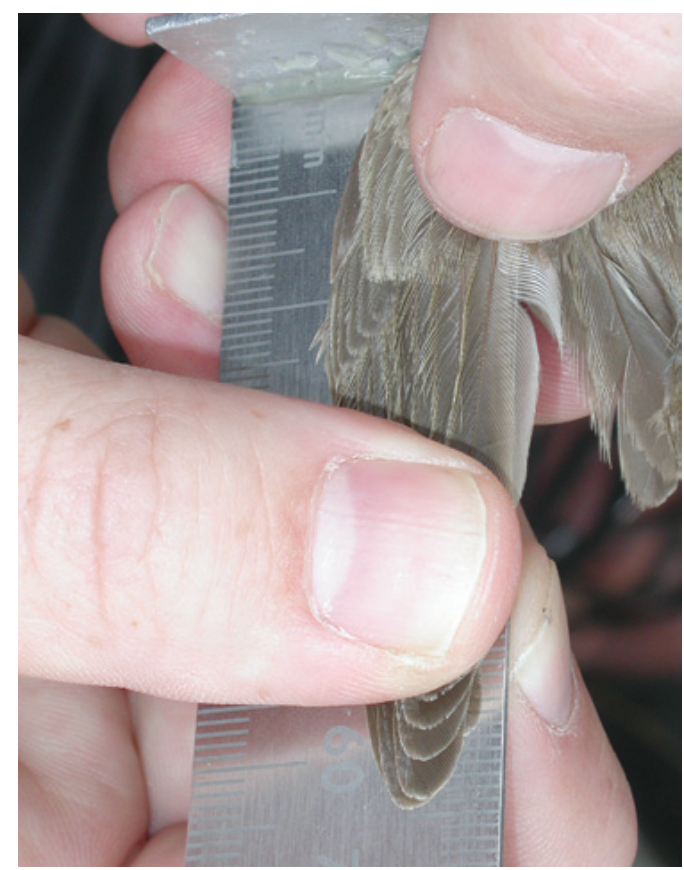

Figur 3. Vingen ble målt til 64 mm. Dette er gansk kort også for bleksanger, hvor Svensson (1992) angir 62-72 mm som variasjonsbredden. Foto: Magne Myklebust. 
med lange ytre stjertfjær; ikke så rund som hos busksanger. Vingekanten var også for rett til å være busksanger, som har en buktende kant når vingen er lagt inn til kroppssiden. Videre skrev Svensson at nebbformen utelukket maurersanger. Dermed var Norges første dokumenterte bleksanger et faktum.

\section{Bleksangerens utbredelse}

Underarten H. p. elaeica, heretter kalt bleksanger, er en utpreget $\emptyset$ stlig art, som forekommer innenfor et stort geografisk område fra de sørøstlige deler av Europa til Sentral-Asia (Fig. 4). Den hekker ikke lengre vest enn Slovakia. Derfra strekker utbredelsen seg sør- og østover gjennom sørlige deler av Ungarn og Romania, nordover langs Svartehavets kyst til Odessa, og sørover gjennom store deler av Balkan. Utbredelsesområdet strekker seg videre østover gjennom Tyrkia, de sørligste delene av Kaukasus, og vestre og nordlige deler av Midtøsten; fra Israel gjennom vestre Syria og nordlige deler av Irak, samt langs Persiabukta. Videre hekker bleksangeren i store deler av Iran, vestre deler av Pakistan, nordover gjennom Afghanistan, sørlige Turkmenistan,
Usbekistan til Kirgisistan, sørvestlige deler av Kasakhstan og nordover langs elvene Amu-Darja og Syr-Darja til områdene øst for Aralsjøen. Forekomsten i de sentrale og østlige delene av Iran er dårlig kjent. Bleksangeren overvintrer i Øst-Afrika, sør til Victoria-sjøen, og i mindre antall langs kysten av den arabiske halvøy. Den er også rapportert fra Bharatpur i India på vinterstid. Bleksanger er påtruffet i noen få land i sentrale og nordlige deler av Europa. De fleste av disse observasjonene er fra Storbritannia, men også land som Irland, Tyskland, Østerrike, Finland, Sverige og Danmark, og nå også Norge har funn av bleksanger (Cramp 1992, Svensson 2001a, Svensson 2001b).

\section{Bleksangeren i Nord- og Vest-Europa}

Til tross for at bleksangeren har en tilbakegang i flere sørøst-europeiske land, finnes det fortsatt gode bestander igjen, spesielt i Tyrkia og Hellas (BirdLife International 2004). Den greske bestanden er estimert til 50000 - 200000 par, mens den tyrkiske bestanden er estimert til hele 3- 6 mill. par (BirdLife International 2004). Med så store forekomster i Hellas og Tyrkia er det

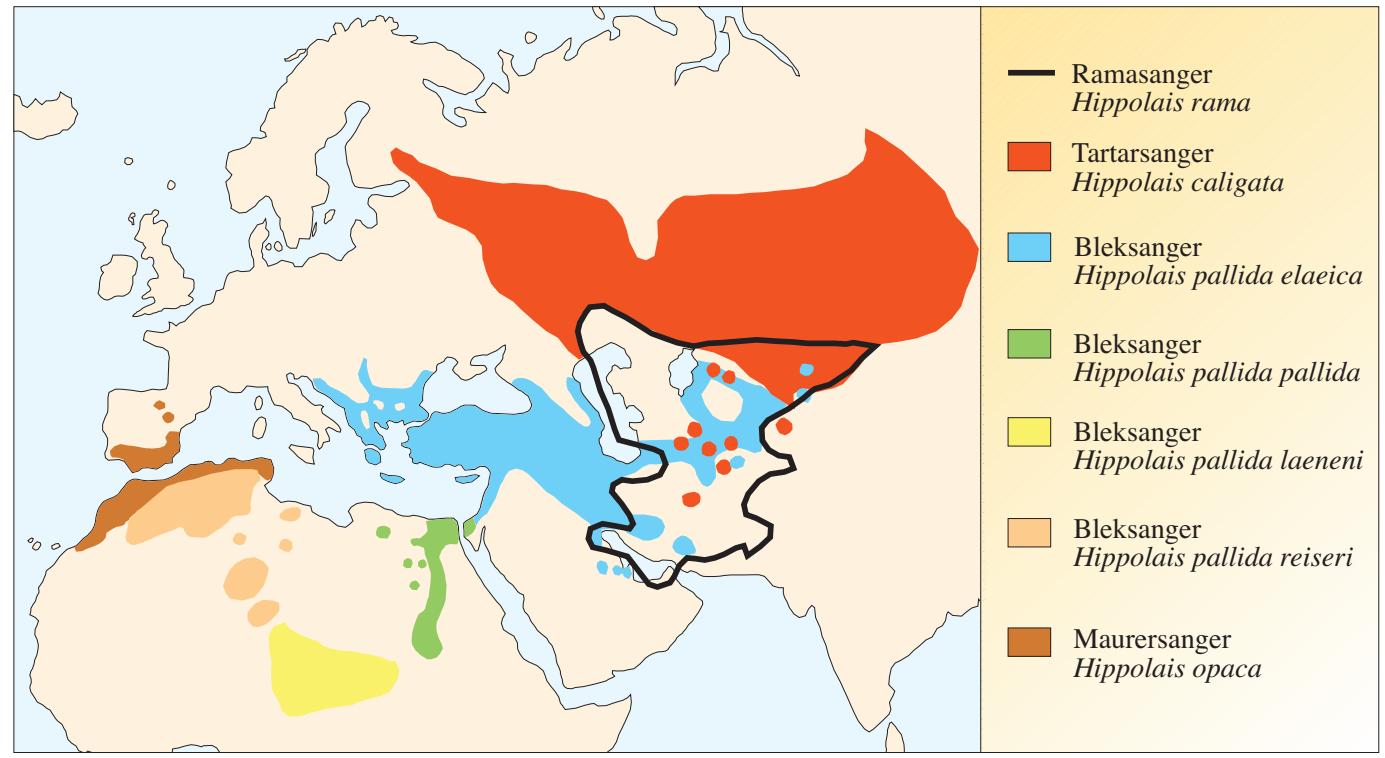

Figur 4. Utbredelsen $i$ hekketiden for bleksanger Hippolais pallida (underartene pallida, elaeica, reiseri og laeneni), maurersanger $\mathrm{H}$. opaca, tartarsanger $\mathrm{H}$. caligata og ramasanger $\mathrm{H}$. rama. For ramasanger er hekkeutbredelsen innenfor svart strek. Kartet er basert på figur 2 i Svensson (2001a) og Svensson (2001b). 
fristende å anta at forlenget vårtrekk og reversert høsttrekk vil kunne gi en rekke funn av bleksanger i Nord- og Vest-Europa. Slik er det imidlertid ikke, og det er tydelig at Alpene og Karpatene danner effektive barrierer i trekktidene, både for bleksangeren og mange andre arter som hekker på Balkan og i Midt-Østen. Tyskland ligger ikke langt unna bleksangerens hekkeområder, men herfra er det likevel bare tre funn i perioden 1883-2000. Østerrike har bare ett overbevisende dokumentert funn av bleksanger, til tross for at arten hekker i nabolandene Slovenia og Ungarn (Svensson 2001 b). England hadde 11 funn av bleksanger t.o.m. 2003 (Rogers 2004), mens Irland hadde fire t.o.m. 1999 (Svensson 2001b). Antall funn av bleksanger (H.p. elaeica) i NordEuropa er også lavt, og i Norden er det totalt bare åtte funn av arten (Tabell 2, Fig. 5-12).

Et eldre funn av blekspottesanger er for tiden under revurdering av den finske sjeldenhetskomitéen, og er derfor å anse som en ubestemt H.opaca/H.pallida. Denne fuglen ble ringmerket 9.9.1957 på Eckerö Signilskär i Åland av P. Linkola. 2004-funnene fra Norge og Sverige er ennå ikke behandlet av de respektive lands sjeldenhetskomitéer, men begge funn er overbevisende dokumentert.

\section{Bleksangerens utseende}

Førsteinntrykket av bleksangeren er at den er en blek og uanselig sanger med få markerte karakterer. Oversiden gir normalt et mer grått enn brunt inntrykk, men i bra lys og med ny fjærdrakt, vil man som regel se et tydelig olivengrønt skjær på oversiden. Dette forsvinner som regel i takt med at fjærdrakten slites utover høsten. Titran-fuglen hadde ikke antydning til olivengrønt i fjærdrakten. Den gav heller et forholdsvis lyst grått inntrykk, også på oversiden. De fleste bleksangerne har antydning til lyse felt på armsvingfjærene, men karakteren er kun gjeldende i ny fjærdrakt, og forsvinner når fjærdrakten slites. Foruten de lyse feltene på armsvingfjærene forkommer en smal, lys strek, eller et lite, lyst felt i varierende grad når vingen er lagt inn til kroppssiden. Dette kommer av at de lyse kantene på armsvingfjærene står i kontrast til de forholdsvis mørke indre håndsvingfjærene. På grunn av slitasje forsvinner denne lyse markeringen, samt det lyse feltet på armsvingfjærene i slutten av mai, begynnelsen på juni. Selv om enkelte individer, uavhengig av slitasje, mangler disse lyse markeringene på armsvingfjærene, kan de, spesielt om våren, likevel brukes i artsbestemmelsen. Undersiden er påfallende lys; nesten hvit med gråfargede kroppssider. Flertallet av individene har svakt konkave nebbsider sett ovenfra. Noen få har rette sider, men uten unntak har ingen konvekse sider,

Tabell 2. Funn av bleksanger Hippolais pallida elaeica $i$ Norden

- 1 ind. (ringm.) 4.-5.10.1983 Luvia Säppi, Satakunta, Finland (M.Hario m.fl.).

- 1 ind. (ringm.) 26.8-2.9.1993 Ottenby, Öland, Sverige (J.Pettersson, C.Cederroth m.fl.)

- 1 ind. (ringm.) 25.9.1993 Eggegrund, Gästrikland, Sverige (S.Persson m.fl.)

- 1 ind. (ringm.) 1.-17.6.1996 Lemland Lågskär, Åland, Finland (G.Andersson m.fl.).

- 1 ind. (ringm.) 6.7.1997 Nidingen, Halland, Sverige (T.Järås, U.Unger, M.Unger m.fl.).

- 1 ind. (ringm.) 1.6.2003 Gedser Fuglestasjon, Danmark (A.Zuschlag, J.W.Christoffersen, H.Lind).

- 1 ind. (ringm.) 12.9.2004 Titran, Sør-Trøndelag, Norge (M.Myklebust, T.Berge, I.Hafstad).

- 1 ind. 9.-10.10.2004 Stora Fjäderägg, Västerbotten, Sverige (V.Nilsson). 
slik man finner blant annet hos maurersanger. Nebbets form kan i visse tilfeller avgjøres i felt, men som hovedregel er denne karakteren kun anvendelig når man har fuglen i hånden. Det er derfor viktig å ta gode bilder av nebbet dersom man er så heldig å fange en bleksanger (Svensson 2001b).

\section{Forvekslingsarter}

Når det gjelder forvekslingsarter er det mest relevant å sammenligne bleksanger med først og fremst maurersanger, ramasanger og tartarsanger Hippolais caligata. Bleksanger er kun marginalt mindre enn maurersanger, med et tynnere, og i mange tilfeller litt kortere nebb, men overlapp finnes. Videre er bleksangerens overside oftest gråere og svakt olivenfarget i ny fjærdrakt. Benene er ikke like kraftige, og stjerten er proporsjonalt kortere. Bleksanger har mørkere håndsvingfjær, i kontrast til armsvingfjærene, som er lysere grå med et, i ny fjærdrakt, forholdsvis lyst felt på armsvingfjærene når vingene er lagt inn til kroppssiden. Bleksangeren vipper stjerten karakteristisk nedover i motsetning til maurersanger, og til dels ramasanger, som holder stjerten stille når den rører seg. Mindre individ av bleksanger kan være meget lik ramasanger, og feltbestemmelse av slike individ krever tid og nøyaktighet. Noe proporsjonalt kortere stjert, lengre håndsvingfjærprojeksjon og annerledes stjertbevegelser er de beste karakterene for å skille artene i felt. Bleksanger har større hode og kraftigere hals, og den beveger seg ikke like raskt og «nervøst» som ramasanger. Den gir derfor inntrykk av å være en tyngre fugl enn ramasanger. Når man har anledning til å sammenligne fuglene i ny fjærdrakt, ser man at bleksangeren er gråere (mindre sandbrun) på oversiden,og med mørkere håndsvingfjær enn ramasanger. Dersom fuglen har et lyst felt på armsvingfjærene, indikerer dette sterkt at vi står overfor en bleksanger, for ramasanger har normalt jevnt brune vinger og kun unntaksvis antydning til denne karakteren. Bleksanger har også jevnt over gråere ben enn ramasangerens mørkere, men fortsatt gråaktige ben. Bleksangeren har en kraftigere nebbrot og en nebbspiss med tendens til å peke nedover, noe som gir fuglen et strengt uttrykk. Dette er en motsetning til ramasangerens vennligere uttrykk som er en følge av dens smalere nebbrot og en rettere og mer symmetrisk nebbspiss (Svensson 2001a, Svensson 2001b).

Større individer av bleksanger kan også forveksles med gråsanger Hippolais languida, som ikke er så grå på oversiden som det navnet og litteraturen kan gi inntrykk av. Gråsangeren har lengre håndsvingfjærprojeksjon enn bleksangeren, og de mørkere grå håndsvingfjærene har kontrasterende lyse spisser, dersom de ikke er alt for slitte. Dette er fraværende hos bleksanger. I likhet med bleksangeren, har også gråsangeren et hvitaktig felt på armsvingfjærene, men feltet er kraftigere og mer konsentrert hos gråsangeren, som også har et større hode, og ofte, men ikke alltid, et kraftigere nebb enn bleksangeren. Gråsangerens stjert er hovedsakelig mørkere grå på oversiden, og de ytterste stjertfjærene (R5 og R6) har mer rent hvitt på spissene enn gjennomsnittlig hos bleksanger. Denne karakteren kan iblant være synlig i felt når fuglen flyr opp. Gråsangeren har bredere stjertfjær, noe som får hele stjerten til å virke bredere enn hos bleksanger. Gråsanger beveger i tillegg stjerten på en karakteristisk måte i forhold til andre Hippolais-arter. Den breier ut stjerten partielt, og svaier med den sideveis som om den satt dårlig fast, noe som aldri forekommer hos bleksanger.

Det er også mulig å forveksle bleksanger med busksanger, som er på samme størrelse og har samme slanke kroppsbygning, og i mange tilfeller veldig like ansiktstrekk. Dette fikk vi erfare da vi først bestemte fuglen på Titran til busksanger. Busksanger har mørkere og brunere overside, og en lengre og mer kileformet stjert enn bleksangeren. Den har også et mørkere undernebb i kontrast til bleksangerens lyse. Ytterkanten på den sammenlagte vingen (fra vingeknoken til spissen) er rundere hos busksanger, noe som passer bedre for en Locustella enn en bleksanger, som har rettere vingekanter. Videre er busksangeren mer gråaktig olivenbrun på hodets sider, hals, bryst, kroppssider og undergump enn 


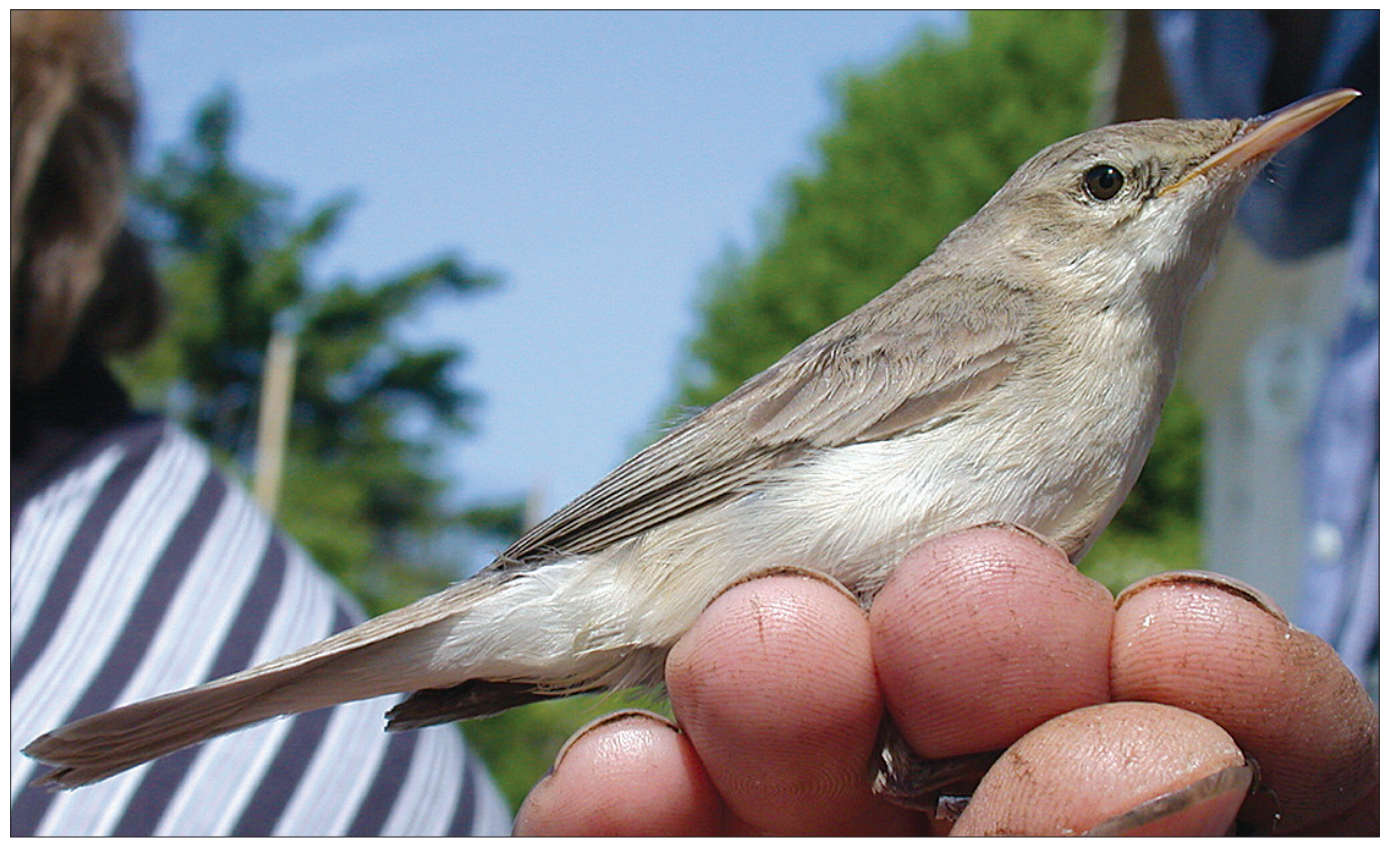

Figur 5. Bleksanger Hippolais pallida elaeica Gedser fuglestasjon, Falster, Danmark 1.6.2003. Det eneste funn av arten i Danmark. Foto: Michael Mosebo Jensen.
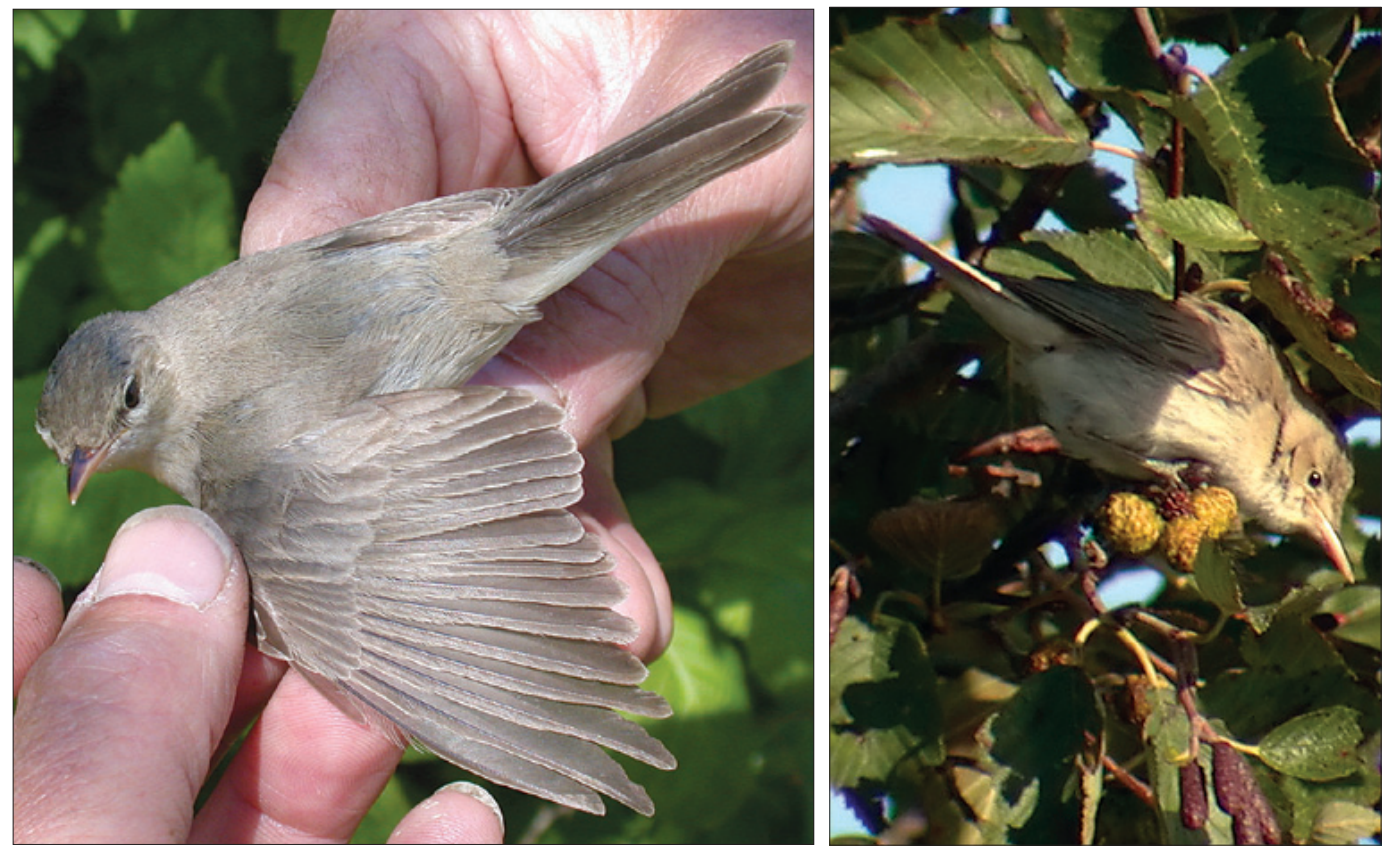

Figur 6 (t.v.). Bleksanger Hippolais pallida elaeica Gedser fuglestasjon, Falster, Danmark 1.6.2003. Foto: Michael Mosebo Jensen. Figur 7 (t.h.). Bleksanger Hippolais pallida elaeica Stora Fjäderägg, Västerbotten, Sverige 9.-10.10.2004. Dette er det siste av totalt åtte funn i Norden pr. desember 2004. Foto: Viktor Nilsson. 

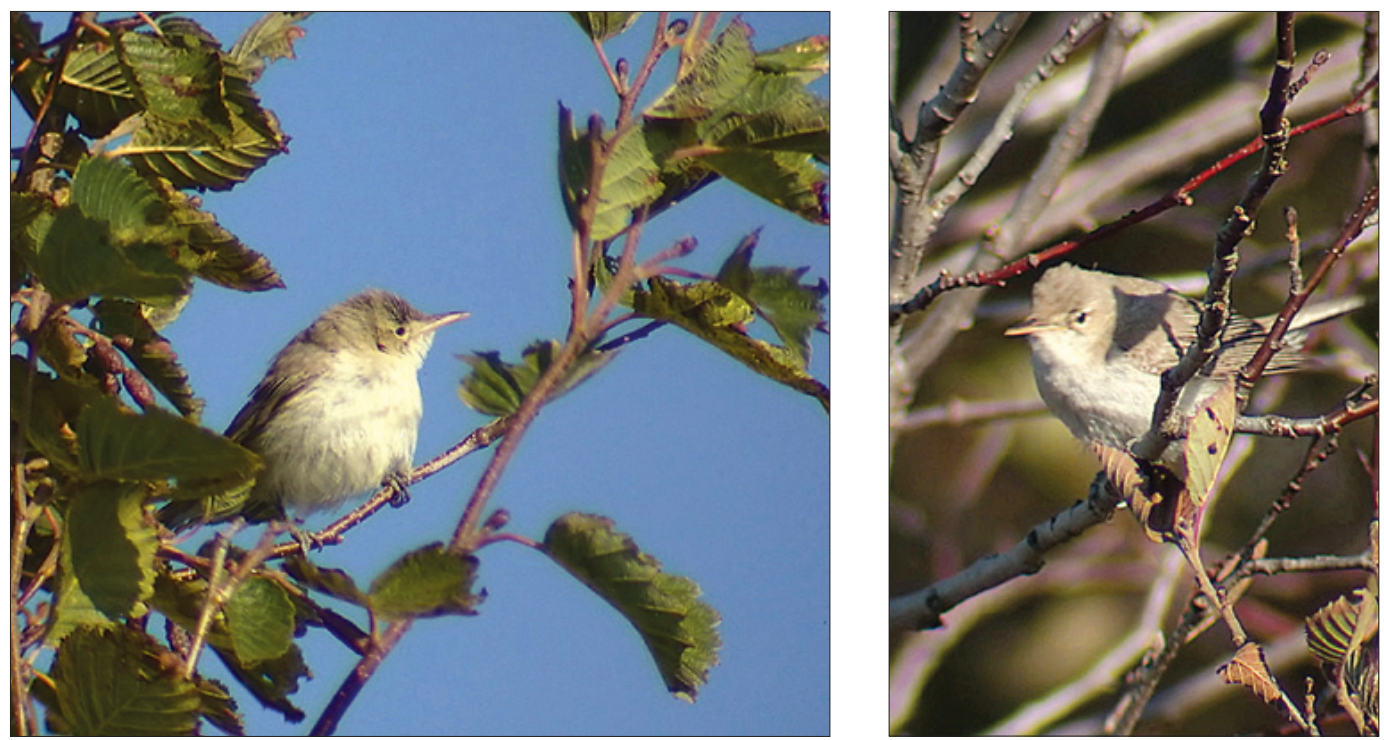

Figur 8 (t.v.) og 9. Bleksanger Hippolais pallida elaeica Stora Fjäderägg, Västerbotten, Sverige 9.-10.10.2004. Av totalt åtte funn i Norden er denne fuglen den eneste rene feltobservasjon. Fuglen ble ikke fanget inn for ringmerking. Foto: Viktor Nilsson.

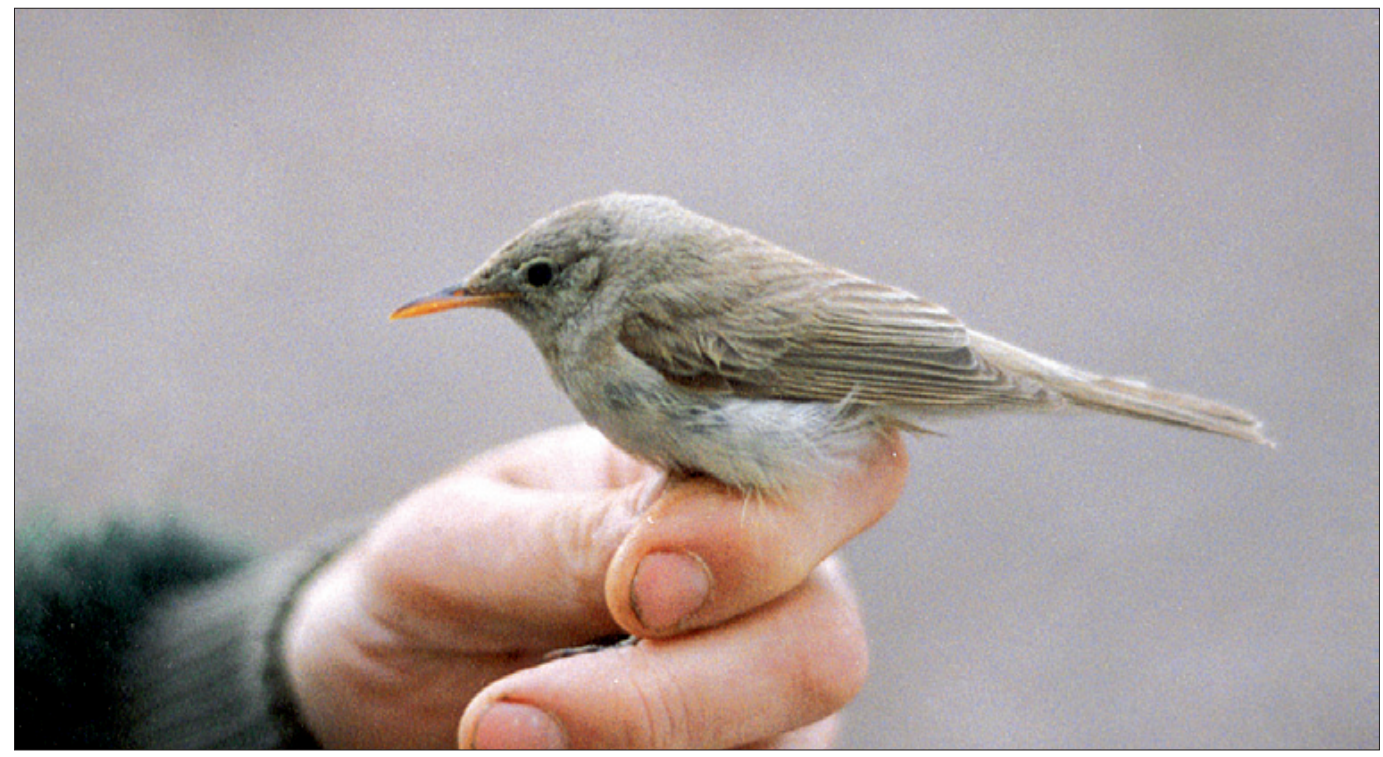

Figur 10. Bleksanger Hippolais pallida elaeica Eggegrund, Gästrikland, Sverige 25.9.1993. Det andre av totalt fire funn av arten $i$ Sverige. Det første funnet i Sverige kom bare en måned tidligere enn fuglen på Eggegrund, se tabell 2. Foto: Mats Westberg. 
bleksangeren. Bleksangerens vippende bevegelser med stjerten er ikke kjent hos busksanger. Denne stjertvippingen er derfor en god karakter for å skille disse artene i felt (Svensson 2001b). Verken busksangerens karaktertrekk til delvis å spre ut stjerten før den kjapt eller langsomt legger den sammen igjen (Golley \& Millington 1996, Baker 1997), eller dens vane med å holde både stjert og hode noe nedoverbøyd når den sitter, forekommer hos bleksanger.

Rørsangerens $\varnothing$ stlige underart Acrocephalus scirpaceus fuscus, er også en mulig forvekslingsart. Noen individer av denne underarten har hvite spisser på de ytre stjertfjærene (Cramp 1992, Shaw et al. 2000). Imidlertid har rørsangere med hvite spisser på stjertfjæren normalt hvitt kun på de ytterste spissene av fjærene, og ikke langs ytterfanen som hos bleksanger. Videre er beina gjennomsnittelig mørkere og gråere, oversiden mørkere og noe brunere enn bleksangeren, og de ensfargede bruntonede vingene savner det lyse feltet på armsvingfjærene.

\section{Med en grå Hippolais i hånden}

Hva gjør du så med en sanger du ikke riktig klarer å plassere? Det er en Hippolais - men hvilken? Oversiden er gråbrun, kanskje med en svak antydning til olivengrønt. Den har forholdsvis mørke grå håndsvingfjær med kontrasterende lyse kanter på tertiærfjærene. Armsvingfjærene har kun antydning til lyse kanter som danner et svakt, lyst felt, samt antydning til en lys tverrstrek på armsvingfjærene når vingen er lagt inn til kroppssiden, slitt som fjærdrakten er i midten av september. Undernebbet er lyst gult uten tegn til noe mørkt nær den svakt nedoverbøyde nebbspissen, noe som allerede har utelukket de fleste individene av ramasanger og tartarsanger. Hva skal man starte med? Nedenfor beskrives fremgangsmåte. Og husk: Ta bilder - mange bilder!

Kontroller avstanden P1 < P2. Er denne 27,5 $\mathrm{mm}$ eller mer, elimineres ramasanger med $96 \%$ sikkerhet. Overlapp forekommer kun innenfor 26,5 - 27,0 mm (Svensson $2001 \mathrm{~b}$ ).
Kontroller innskjæringene på ytterfanen av håndsvingfjærene. Kun hos noen få unntak kan det finnes antydning til innskjæring på P6 (se tabell 2). Hos ramasanger har $75 \%$ en fremtredende og tydelig innskjæring på P6, og bare $5 \%$ mangler denne innskjæringen. Tartarsanger har en mellomting. Hvor dypt innskjæringen på ytterfanen går når vingen er sammenlagt, er en «i hånden karakter». Hos bleksanger er innskjæringen i høyde med, eller litt innenfor spissen av armsvingfjærene, mens den hos ramasanger ligger dypere og er tydelig innenfor spissen av armsvingfjærene.

Kontroller videre tegningene på de ytterste stjertfjærene (Fig. 13), da disse kan skille bleksanger fra ramasanger og tartarsanger. Hos bleksanger er det hvite konsentrert, iblant til og med begrenset, til innerfanen av R6 og R5. En annen tendens hos bleksanger, er at den mørke, sentrale delen av fjæren løper ut som en smal tunge langs skaftet og når nesten helt ut til spissen. Hos ramasanger og tartarsanger dekker det hvite på R6 normalt mer av fjærspissen, og den mørkere delen av fjærens sentrum munner ikke ut $i$ en tunge langs skaftet mot spissen av fjæren. Videre har ramasangerens R5 ofte en ganske stor, nærmest kileformet hvit spiss. Denne karakteren forekommer aldri hos bleksanger. Et fåtall individer (anslagsvis mindre enn $5 \%$ ) har intermediære stjerttegninger (Svensson 2001b).

$\mathrm{P} 2=5 / 6$ eller $=6$ påtreffes anslagsvis hos halvparten av bleksangerne. Ganske ofte er P1 kort og smal, i motsetning til hos ramasanger, der den som oftest er lang og bred. For å skille bleksanger fra maurersanger er nebbformen sett ovenfra, den beste karakteren. $85 \%$ av bleksangerne har konkave sider, og de $\varnothing$ vrige har rette sider. Ingen har konvekse sider, slik man ofte finner hos maurersanger. For å skille disse små grå Hippolais-artene fra hverandre, og fra andre forvekslingsarter, er det også viktig å måle alle biometriske mål som tarslengde, stjertlengde, forholdet mellom stjert og vinge, nebbets bredde og lengde, og vingeformel (P1 $>$ PC, $\mathrm{P} 6<$ vingespissen, $\mathrm{P} 10<$ vingespissen, 
$\mathrm{S} 1<$ vingespissen, $\mathrm{P} 1<\mathrm{P} 2, \mathrm{P} 2$ = $\mathrm{P}$ ?). Det er videre viktig å ta bilder av stjerttegninger og andre karakterer. Se tabell 3 for biometri og vingeformel hos bleksanger.

\section{Takksigelser}

Stor takk til Lars Svensson for hjelp til å artsbestemme denne utfordrende fuglen, samt for tillatelse til å bruke hans figurer som er publisert i Birding World (Svensson 2001a) og Vår Fågelvärld (Svensson 2001b). En takk går også til Kjetil Aa. Solbakken og Alf Tore Mjøs som først fikk mistanke om at det dreide seg om bleksanger. Takk til Christian Cederroth fra den svenske sjeldenhetskomitéen for oversikt over funn av Hippolais pallida elaeica og Hippolais opaca i Sverige, og takk til Visa Rauste i den finske sjeldenhetskomitéen for tilsvarende oversikt fra Finland. En stor takk går også til fotografene Viktor Nilsson, Stefan Persson, Mats Westberg, Michael Mosebo Jensen og Kari Soilevaara for å ha bidratt med bilder til artikkelen. Gunnar Flor Hallgrimsson og Johann Oli Hilmarsson takkes for oversikt over status for grå Hippolais-sangere på Island

\section{Referanser}

Baker, K. 1997. Warblers of Europe, Asia and North Africa. Christopher Helm, A. \& C. Black, London. $400 \mathrm{~s}$.

Bentz, P.-G. \& Clarke, A.W. 1990. Sjeldne fugler i Norge i 1988. Rapport fra Norsk Sjeldenhetskomité for fugl (NSKF), NZF og NOF. - Vår Fuglefauna 13: 131-143.

BirdLife International 2004. Birds in Europe. Population estimates, trends and conservation status. Cambridge, UK: BirdLife International (BirdLife Conservation Series No. 12).

Cramp, S. 1992. The Handbook of the Birds of Europe, the Middle East and North Africa. The Birds of the Western Palaearctic. Volume VI: Warblers. Oxford University Press, London.

Gjershaug, J.O., Thingstad, P.G., Eldøy, S. \& Byrkjeland, S. 1994. Norsk fugleatlas. Norsk Ornitologisk Forening. Klæbu. $551 \mathrm{~s}$.

Golley, M. \& Millington, R. 1996. Identification of Blyth's Reed Warbler in the field. - Birding World, 9: 351-353.

Gustad, J. 1994. Sjeldne fugler i Norge i 1992. - Vår Fuglefauna 17: 259-278.

Knox, A.G., Collinson, M., Helbig, A.J., Parkin, D.T. \& Sangster, G. 2002. Taxonomic re- commendations for British birds. - Ibis 144: 707-710.

Osborn, K. 1993. The Shetland Hippolais warbler. - Birding World 6: 437-438.

Rogers, M.J. and the Rarities Committee 2004. Report on rare birds in Great Britain in 2003. British Birds 97: 558-625.

Shaw, D., Holt, C. \& Maggs, H. 2000. The Caspian Reed Warbler on Fair Isle. - Birding World 13: 315-317.

Solbakken, K.A. \& Myklebust, M. 2000. Gråhodespurv på Titran i oktober 1999 - det første funnet i Norge. - Vår Fuglefauna 23: 108-111.

Svensson, L. 1992. Identification Guide to European Passerines. 4th Edition. Lars Svensson, Stockholm. 368 s.

Svensson, L. 2001 a. Identification of Western and Eastern Olivaceous, Booted and Sykes's Warblers. - Birding World 14: 192-219.

Svensson, L. 2001 b. Identifiering av små grå Hippolais-sångare. - Vår Fågelvärld 60: 16-30.

Tabell 3. Biometri og vingeformel hos bleksanger Hippolais pallida elaeica (Svensson 2001b).

\section{Biometri hos bleksanger (alle mål i mm)}

Vingelengde: hann 64-72, $\mathrm{m}=67,4(\mathrm{n} 131)$ hunn $62-69, \mathrm{~m}=62,5$ (n 38)

Stjertlengde $(R)$ : hann 46-56,5, $\mathrm{m}=51,9$ (n 131) hunn $46-55, \mathrm{~m}=50,6$ (n 39)

Forholdet stjert/vinge (x100): 67,6-83,3, $\mathrm{m}=77,2$ (n 196)

Tars: $19,0-21,8, \mathrm{~m}=20,8$ (n 137)

Nebb: $14,1-17,5, \mathrm{~m}=15,9$ (n 198)

Nebbhoyde: $2,6-3,6, \mathrm{~m}=3,2$ (n 178)

Nebbredde: $3,6-4,9, \mathrm{~m}=4,2$ (n 185)

\section{Vingeformel hos bleksanger (alle mål i mm)}

- P1 > PC 1,5-7,5 (oftest 3-6)

- $\mathrm{P} 2<$ vingespiss 2,5-7

- P6 < vingespiss 2-6,5

- $\mathrm{P} 10<$ vingespiss $11-15,5, \mathrm{~m}=12,9$

- $\mathrm{S} 1<$ vingespiss $13,0-18,0, \mathrm{~m}=14,9$

- $\mathrm{P} 1<\mathrm{P} 226,5-33,0, \mathrm{~m}=30,4$

- $\mathrm{P} 2=6 / 7(42 \%),=6(32 \%),=5 / 6(21 \%),=$ $7(5 \%)$

- Svak antydning til innskjæring av ytterfanen på P6 finnes bare hos 5,5\%, mens kun 0,5\% har tydelig innskjæring. Resterende $94 \%$ har ikke innskjæring av ytterfanen på P6. Omkring $5 \%$, hvorav alle var ungfugler, hadde dårlig utviklet innskjæring også på P5. 


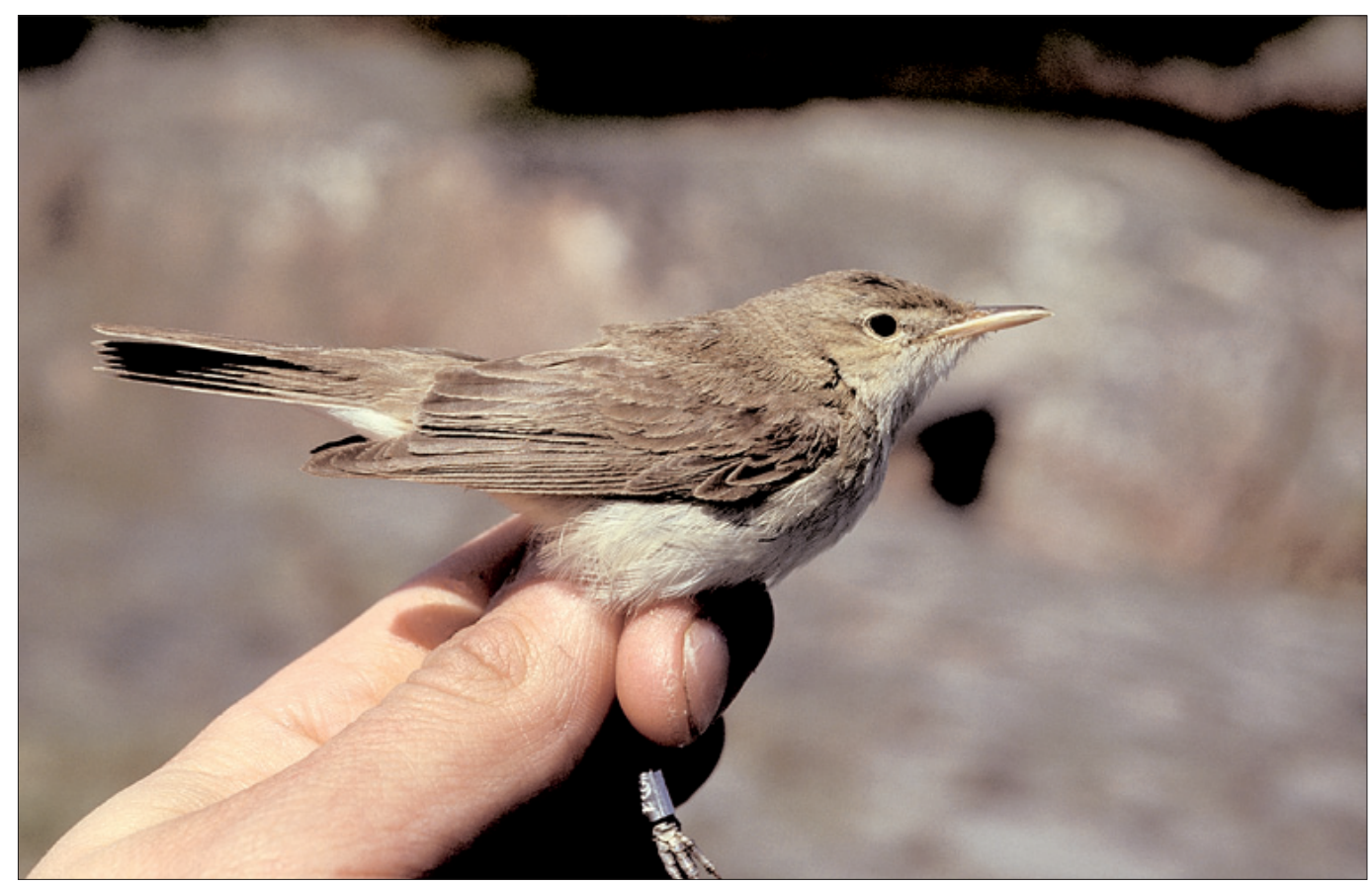

Figur 11. Bleksanger Hippolais pallida elaeica Lemland Lågskär, Åland, Finland 1.-17.6.1996. Foto: Kari Soilevaara.

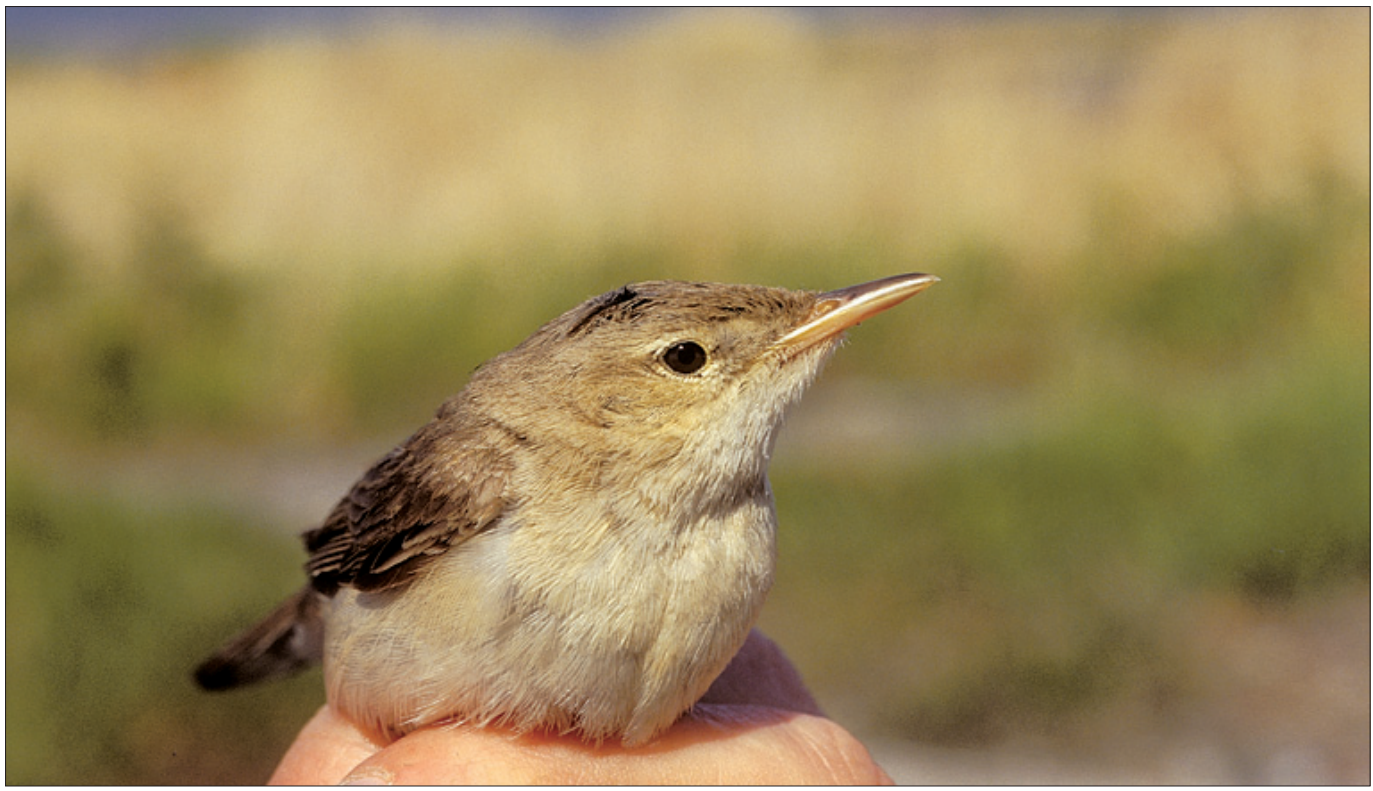

Figur 12. Bleksanger Hippolais pallida elaeica Lemland Lågskär, Åland, Finland 1.-17.6.1996. Foto: Kari Soilevaara. 


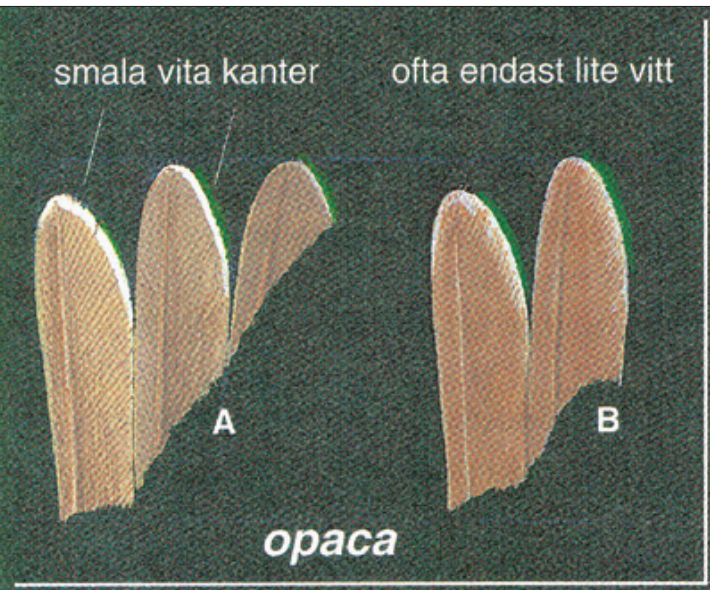

tydligt vitt
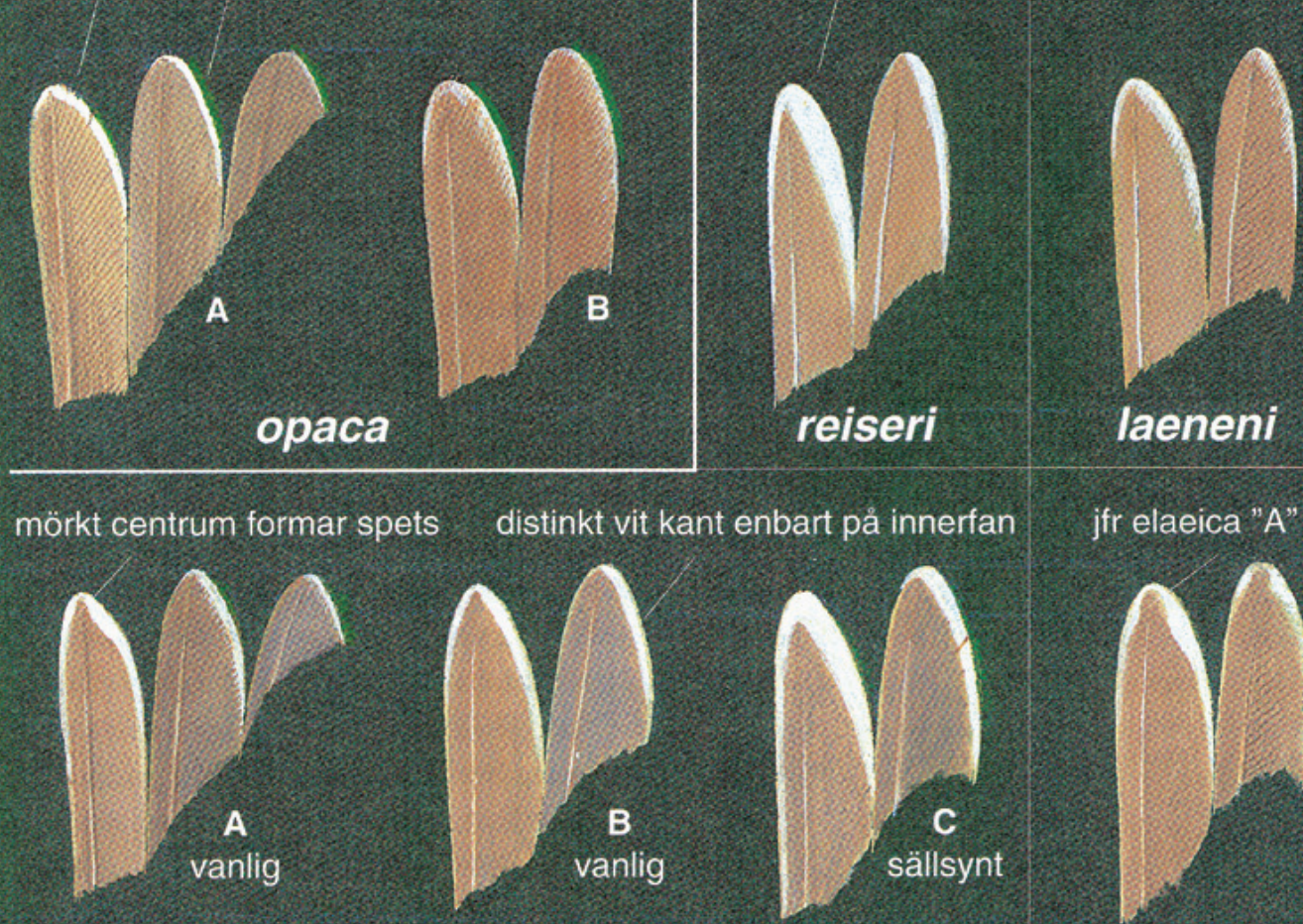

elaeica

pallida

ofta mycket vitt pá spetsen av R5

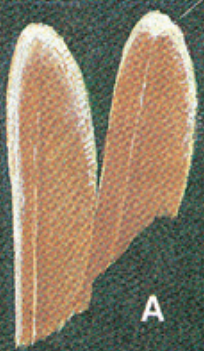

diffust

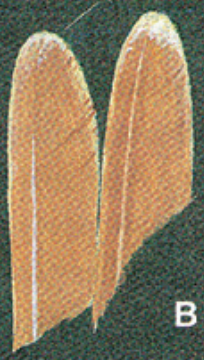

rama

\section{diffust}

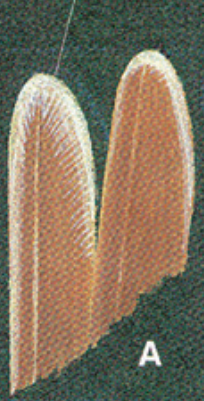

jfr elaeica "A"

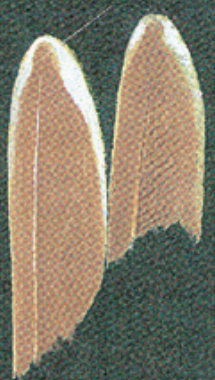

ofta endast

lite vitt

\section{caligata}

Figur 13. Typiske ytre stjerfjer hos maurersanger Hippolais opaca, bleksanger $\mathrm{H}$. pallida av underartene reiseri, laeneni, elaeica og pallida, ramasanger $\mathrm{H}$. rama og tartarsanger $\mathrm{H}$. caligata. Legg merke til hovedmønsteret, forekomsten av hvitt på spissene og kontrasten i grensen mellom morkt og hvitt. Alle individer er ikke like typiske. Illustrasjon: Lars Svensson. 